\title{
Kinetic Interpretation and Optimal Operating Conditions of VGO Mild HydroCracking
}

\author{
Asem M. AL Jarrah \\ Natural Resources and Chemical Engineering Department \\ Tafila Technical University, Tafila, Jordan \\ asem.aljarrah@yahoo.com
}

\begin{abstract}
The application of mild hydro cracking using former hydrodesulfurization commercial units to produce low sulfur high cetane number Diesel is a growing area of interest. The total pressure and the type of catalyst used are some of constrains associated with the quality of the product obtained from mild conversion. This paper focuses on the effect of fluid dynamics and vaporization on the product quality. Two sets of experiments have been carried out in a pilot plant to obtain information on the product and to adjust the kinetics constants. In addition, a hot separation system has been used to obtain samples of gas and liquid phase at reaction conditions. In this way the gas and liquid properties in the reactor were evaluated. The mass and energy balance for the trickle bed reactor were performed by using a simplified lump of kinetics. Additionally a commercial simulation package was used to calculate the vaporization. Information from cold model was used to carry out old up measurements. The information was important in order to interpret the vaporization and the type of molecules present in gas and in liquid phases. Using the kinetics model it was shown that the increase in vaporization reduce the gas phase residence time, hydrogen partial pressure, and hydrogen hydrocarbons ratio. By modifying the mild hydrocracking reaction temperature, the cetane number of the diesel fraction produced initially increases and then decrease when temperature is risen. Aromatic and naphthenes increase in the lighter fractions at high conversion.
\end{abstract}

Keywords: Cetane Number, Vacuum Gas Oil, Mild Hydrocracking, Hot Separation.

\section{INTRODUCTION}

Mild hydrocracking (MHCK) operation has been tested in a broad range of conversion levels and feed stocks. A new generation of catalysts capable of reducing nitrogen and aromatics and increasing hydrocracking activity has recently been introduced. The 2000's bring forward many challenges for the refining industry with more stringent environmental specifications for fuels, especially in diesel production and a general trend toward converting more difficult feedstocks. These changes are making hydrogen availability and catalyst stability a limiting factor in many refineries. There are ever increasing incentives to apply in optimal conditions the new catalyst technologies in the installed (old) hydrodesulfurization (HDS) units before the fluid catalytic cracking (FCC), operating at medium pressure. In the past, operation of these units took place at medium hydrogen partial pressure and low hydrogen consumption. Hydrodesulfurization of straight run Gas Oil occurs with slight hydrogenation of the poly-aromatics, a reaction that reduces the hydrogen partial pressure along the reactor. In addition, a slight conversion of $370^{\circ} \mathrm{C}+$ cut into lighter material occurred, with near constant hydrocarbon vaporization throughout the reactor. In mild hydrocracking, the hydrogenation and hydrocracking reaction occurs with changes in hydrogen partial pressure and vaporization. This paper deals with a pilot plant study and vaporization measurement to show the effect of vaporization in diesel quality, and on HDS, poly-aromatics saturation (HDA) and mild hydrocracking (MHCK) reactions. Previous experience processing cracked feed stocks using a particular technology named HHC was published elsewhere [1,2].

\section{EXPERIMENTAL AND SIMULATION}

Three different types of experiments have being performed. 1) Conventional pilot plant tests were performed to determine the effect of temperature in conversion and vaporization at constant initial hydrogen partial pressure that complement previous studies carried out at constant temperature but different partial pressure. Also, one test changing the hydrogen partial pressure was made to confirm 
previous results at high temperature; 2) Hot separation carried out to fractionate the feed and the reaction product at the operating conditions used in the trickle bed reactor. 3) Simulation of the small pilot plant reactor fluid dynamics using a cold model. PRO IITM, process simulation package was used to predict vaporization and gas and liquid properties of the phases at the reaction conditions. For that three pseudo-component were defined for VGO and one for the liquid product (as an example, the properties in Table 1).

\subsection{Pilot Plant}

The effects of temperature in MHCK have been studied in small scales pilot plant. This unit includes a $100 \mathrm{~cm}$ down -flow fixed bed reactor that operates isothermally. The hydrogen and the hydrocarbon feed were preheated before entering the reactor. After reaction, the liquid product was fractionated and analyzed using conventional ASTM methods. In addition, a Mass Spectrometry coupled with gas Chromatography (GC MS) was used to measure the aromatic paraffinic and naphtenic compounds distribution in feed and in products. The pilot plant scheme and the catalytic system properties used can be seen in reference [3]. The results of present experiment are reported in Table 2. The operating conditions for the present series of experiments are also shown in the same table (Temperature varied from $370^{\circ} \mathrm{C}$ to $420^{\circ} \mathrm{C}$, Pressure 80 bars, LHSV: $0.5 \mathrm{~h}^{-1}$ ). Hydrogen purity used was $100 \%$. The catalytic system was diluted with $50 \%$ inert material, and used at particle size of $0.1 \mathrm{~cm} \mathrm{x} 0.1 \mathrm{~cm}$ (cylinder). This special precaution was taken to insure proper fluid dynamics according to the De Brujin (1976-(4)) results. An additional test was carried out at $80 \mathrm{~atm}$ and $420^{\circ} \mathrm{C}$, LHSV $0.5 \mathrm{~h}^{-1}$ ) using $\mathrm{H} 2$ purity of $80 \%$.

\subsection{Hot Separation}

The feedstock and two products were passed through a hot separator system (HSS) set at one of the temperatures and pressure used for the pilot plant (T:400 ${ }^{\circ} \mathrm{C}, \mathrm{P}: 80$ bar, $\mathrm{H} 2$ / HC:400 Nl /l) to obtain the gas and liquid phases. The gas phase was condensed and the liquid hydrocarbons recovered for further analysis. Liquid phase was cooled and stripped to obtain hydrocarbons for analysis (see scheme in figure 1). Using a laboratory distillation unit (TBP), four cuts were obtained: $\mathrm{C} 5-350^{\circ} \mathrm{C}$, $350-400^{\circ} \mathrm{C}, 400-450^{\circ} \mathrm{C}$ and $450-500^{\circ} \mathrm{C}$. Sulfur aromatics naphthenes and paraffins were measured on them. Hot separation system produced sample of gas phase and liquid phase at one temperature to compare the fluid dynamics. Analytical results are shown in Tables 3, 4 and 5 for the different cuts. Other physical measurements such as viscosity, molecular weight, and surface tension were conducted to determine all the properties required by the PRO II ${ }^{\mathrm{TM}}$ process simulation package.

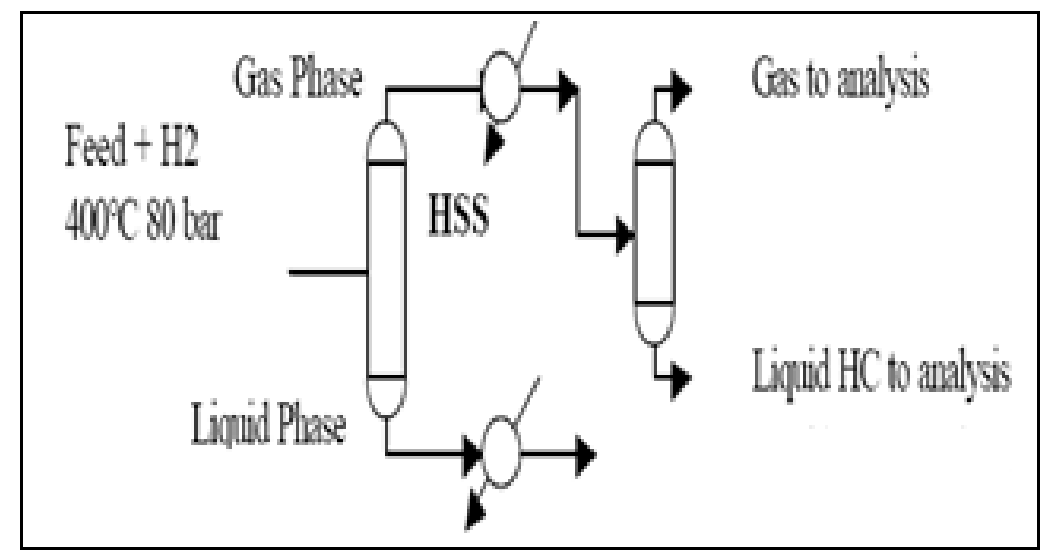

Figure1. Scheme of the hot separator system.

\subsection{Definition of Pseudo -Components}

The information generated by the analysis of the narrow cuts $\left(50^{\circ} \mathrm{C}\right)$ was used to define pseudocomponents in PROII simulation. The typical properties required for PROII to use the RedlichKwong-Soave State Equation are listed in Table 3 for cut number III, as an example. Molecular weight, viscosity, mean average boiling point (T50), surface tension, were measured (Table 1). The critical properties (T, P and V), specific heat capacity and enthalpy of formation were calculated using the correlation of Joback and Reid [1987, 5]. The Acentric Factor was calculated according to Lee and Kesler [1975,6]. This information was introduced into the program for feed and products with the same pseudo-component 
Table1. Pseudo-component properties

\begin{tabular}{|c|c|}
\hline \multicolumn{2}{|c|}{ Pseudo-component Number III $\left(400-450{ }^{\circ} \mathrm{C}\right)$} \\
\hline Molecular weight g/gmol & 235 \\
\hline Gravity $(60 / 60)$ & 0.8814 \\
\hline Mean Boiling Temp ${ }^{\circ} \mathrm{C}$ & 432 \\
\hline Acentric Factor & 0.598 \\
\hline Critical Pressure N/m2 $^{\circ}$ & $2.1 \mathrm{E}+06$ \\
\hline Critical Temperature $^{\circ} \mathrm{C}$ & 669 \\
\hline Compressibility factor $^{\circ}$ & 0.987 \\
\hline Critical Volume cm3/gmol & 0.654 \\
\hline Vaporize. Entalphy $(\mathrm{J} / \mathrm{gmol})$ & 64067 \\
\hline Viscosity Ns/m2 & $2.44 \mathrm{E}-03$ \\
\hline
\end{tabular}

\subsection{Cold Model}

Previous experiments done with a cold model trickle bed reactor [7] for simulating the HDS of VGO operated with air and octane. They have allowed us to determine gas and liquid hold ups, and wetting properties. But in the present work, the measured properties of the gas and liquid phase in MHCK conditions demonstrated an important departure in gas phase properties from air - octane properties blend used in previous work. For that a new set of experiments using propane-hydrogen and octane were carried out to verify the holdup measurements. The fluid dynamics study is in progress and the complete results will be presented in future publications. Some information is commented the following sections.

\section{AnAlysis OF THE ReSUlts}

In Table 2 the pilot plant results are shown. The first column lists the properties for the feed (total cut $\left.350-500^{\circ} \mathrm{C}\right)$. The next columns present the product quality $\left(\mathrm{C} 5-500^{\circ} \mathrm{C}\right)$ for different $\mathrm{MHCK}$ conversions. The NMR analysis allowed to distinguish the mono-di-and tri rings aromatics and the mono-di-and tri rings cyclo-paraffins. Table 2 indicated that the feed (VGO) has a high sulfur, nitrogen and aromatics content (it is a blend of 40-50\% straight run VGO +60-50\% of Delayed Coker VGO). The aromatic distribution indicated a high proportion of di and tri-rings aromatics. All experiments were made at the same total pressure $(80 \mathrm{~atm}), \mathrm{H} 2 / \mathrm{HC}$ ratio and space velocity but changing the temperature. It can be see that going from 360 to $420^{\circ} \mathrm{C}$, the MHCK conversion (VGOo -VGOf / VGOo) increases from 3 to $33 \%$ by weight, sulfur is reduced from $3800 \mathrm{ppm}$ to $500 \mathrm{ppm}$ and aromatics reduce from 43.5 to $35 \%$ wt. Paraffin and cyclo-paraffinsincrease accordingly. Vaporization increases when temperature increases and the lighter the product the higher is the vaporization. In that way more HC (hydrocarbons) compounds get in gas phase. Along the reactor, VGO is converted into lighter materials that are additionally vaporized at the reactor conditions. To calculate the HC concentrations in gas and liquid phase, the vaporization of the feed and two products were measured using the hot separator system.

Table2. Feed and products quality.

\begin{tabular}{|c|c|c|c|c|c|c|c|}
\hline \multicolumn{7}{|c|}{ Feed and Product quality in a Typical MHCK operation } \\
\hline Temperature oC & & 360 & 370 & 380 & $\mathbf{3 9 0}$ & $\mathbf{4 0 5}$ & $\mathbf{4 2 0}$ \\
\hline LHSV h & & 0.75 & 0.75 & 0.75 & 0.75 & 0.75 & 0.75 \\
\hline Conversion 500oC+ & 0 & 3 & 5 & 16 & 25 & 29 & 33 \\
\hline Properties & Feed & Prod 1 & Prod 2 & Prod 3 & Prod 4 & Prod 5 & Prod 6 \\
\hline Density g/cc & 0.9102 & 0.8982 & 0.8999 & 0.8999 & 0.8999 & 0.8999 & 0.8999 \\
\hline Sulfur wt\% & 1.90 & 0.38 & 0.19 & 0.10 & 0.08 & 0.07 & 0.05 \\
\hline Nitrogen wt ppm & 4500 & 2800 & 1800 & 870 & 600 & 300 & 100 \\
\hline n+isoparafins & 23.09 & 25.60 & 24.50 & 25.50 & 26.00 & 27.10 & 29.00 \\
\hline Monociclop wt\% & 14.50 & 12.60 & 17.13 & 17.14 & 18.40 & 19.20 & 20.40 \\
\hline Dicicloparaf wt\% & 12.10 & 13.40 & 14.14 & 13.00 & 12.18 & 12.66 & 12.44 \\
\hline Triciclopar wt\% & 6.80 & 6.90 & 5.80 & 5.20 & 4.50 & 3.32 & 3.12 \\
\hline Mono arom wt\% & 20.10 & 23.60 & 27.10 & 29.45 & 32.56 & 32.13 & 30.67 \\
\hline Di aromat wt\% & 20.20 & 12.60 & 10.11 & 8.87 & 7.14 & 6.13 & 5.12 \\
\hline Triaromat wt\% & 2.20 & 1.80 & 0.89 & 0.20 & 0.00 & 0.00 & 0.00 \\
\hline Tetraromat wt\% & 1.01 & 0.00 & 0.00 & 0.00 & 0.00 & 0.00 & 0.00 \\
\hline Thiophenes Ar & 3.60 & 0.87 & 0.43 & 0.23 & 0.12 & 0.11 & 0.08 \\
\hline
\end{tabular}


(HSS) at one operating condition (see Figure 2). This amount of HC in the gas phase (after being condensed) was measured as well as the liquid phase, and the vaporization calculated. Figure 2 shows the mass vaporized (mass of $\mathrm{HC}$ in gas phase /total amount of $\mathrm{HC}$ in the feed or the product). It can be seen that the higher the operating temperature the higher $\mathrm{HC}$ content in gas phase. This affects the rate of reactions, since the hydrogen concentration and the hydrocarbon concentration are different in gas phase. Vaporization goes from 52 for feed, to $71 \%$ wt for 33\%wt of MHCK conversion. PROII predicts 55 and $82 \% \mathrm{wt}$, respectively, that is higher than experimentally measured (fig 2). The gas phase and the liquid phase hydrocarbons were distillated to obtain four "pseudocomponents": I) C5 to $350^{\circ} \mathrm{C}$, II) 350 to $400^{\circ} \mathrm{C}$, III 400 to $450^{\circ} \mathrm{C}$ and IV 450 to $500^{\circ} \mathrm{C}$. The fractions were analyzed and the products properties distribution are presented in Tables 3, 4, and 5 for feed, $16 \%$, and 33\%wt of conversion respectively. The NMR analysis of aromatics and naphthenes in the fraction report more than $+/-5 \%$ error, if all the fractions are added and compared with the amount present in the total cut (non distillated gas and liquid sample). For that the paraffins concentrations have being adjusted to balance the mass to $99-100 \%$ (wt). They might only used for understand the qualitative trends. The mass balance and the properties for the feed, 16, and $33 \mathrm{wt} \%$ of MHCK are shown in tables 3, 4 and 5. Table 3 shows the results for VGO. Here the total mass is $100 \%$ because there is no reaction (only high pressure high temperature separation). Gas phase has lower sulfur and naphthenes and similar aromatics content than liquid phase. Lighter is the cut lower are the sulfur and the paraffins content. The aromatic distribution looks quite flat. Table 4 shows the case of $16 \%$ wt conversion, where there was a $97 \%$ of feed liquid mass. Here the 3\%wt of C5- are gases produced by cracking, they were not counted in the liquid product.

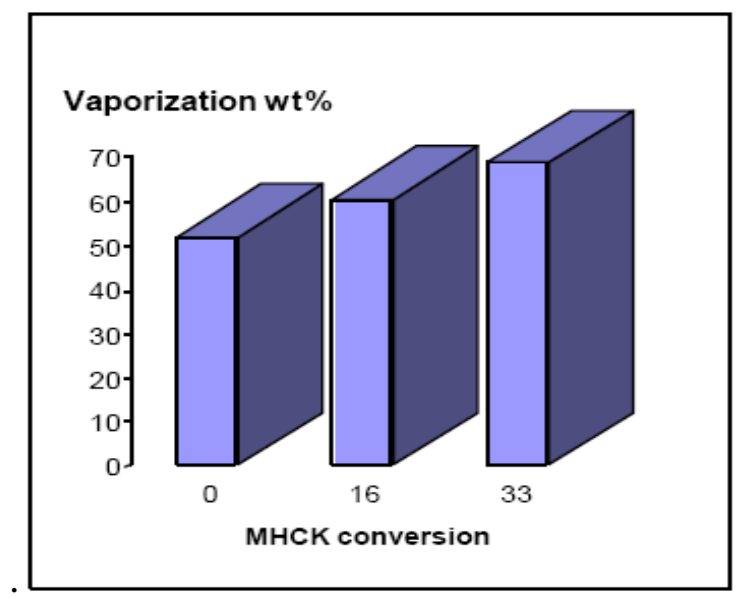

Figure2. MHCK effect on vaporization.

Table3. Compound distribution in the cuts II, III and IV for the feed.

\begin{tabular}{|c|c|c|c|c|c|c|}
\hline \multicolumn{7}{|c|}{ Compound Distribution in Feed } \\
\hline COMPOUND & $350-400$ & $400-450$ & $450-500$ & TOTAL & Gas Phase & Liquid-Phase \\
\hline Mass Distribution & 35.0 & 35.0 & 30.0 & 100 & 52.5 & 47.5 \\
\hline Sulfur wt ppm & 15560 & 19140 & 22850 & 19000 & 16559 & 21671 \\
\hline Parafins wt\% & 20.7 & 22.8 & 25.70 & 23.0 & 21.0 & 23.5 \\
\hline Naphthene wt\% & 36.0 & 33.0 & 30.3 & 31.2 & 34.7 & 31.3 \\
\hline Aromatics wt\% & 42.2 & 43.6 & 43.8 & 43.0 & 43.8 & 43 \\
\hline
\end{tabular}

Table4. Product properties at $16 \%$ of MHCK conversion.

\begin{tabular}{|c|c|c|c|c|c|c|c|}
\hline \multicolumn{7}{|c|}{ Compound Distribution for 16 wt\% of conversion } \\
\hline COMPOUND & C5-350 & $350-400$ & $400-450$ & $450-500$ & TOTAL & Gas Phase & Liqu phase \\
\hline $\begin{array}{c}\text { Mass } \\
\text { Distribution }\end{array}$ & 13.4 & 41.2 & 31.0 & 14.0 & 97.0 & 60.7 & 39.3 \\
\hline Sulfur wt\% & 675 & 812 & 1090 & 1660 & 1000 & 790 & 1100 \\
\hline Paraffins wt\% & 32 & 28 & 26 & 23 & 26 & 25.3 & 26.2 \\
\hline Naphthene wt\% & 38 & 34 & 34 & 35 & 35 & 35.8 & 34 \\
\hline Aromatics wt\% & 30 & 38 & 40 & 42 & 39 & 38 & 39 \\
\hline
\end{tabular}

Table 4 shows that at $16 \%$ of conversion the gas phase still contain much lower sulfur and paraffins, but similar aromatics than liquid phase Aromatics are concentrated in the heaviest VGO fractions (increase from II to IV). Paraffins show a different pattern. Naphthenes distribution is quite constant. 
Table 5 shows the case of $33 \%$ of conversion where the total liquid recovered was $96 \%$ wt, being the remaining $4 \mathrm{wt} \% \mathrm{C} 5$ - gases formed by MHCK. Table 5 shows that the gas phase and the lighter cut (I) contain the lowest sulfur and Naphthenes, and the highest aromatics than in liquid phase or heavier cuts. Aromatics seem to be concentrated in the lighter material (I), being produced by MHCK reaction. Naphthenes decrease when the molecular weight increases (I to IV) and paraffins distribution is nearly constant.

Table5. Product properties at 33\% wt of MHCK conversion.

\begin{tabular}{|c|c|c|c|c|c|c|c|}
\hline \multicolumn{7}{|c|}{ Compound Distribution for 33 \% of conversion } \\
\hline COMPOUND & $\mathbf{C 5 - 3 5 0}$ & $\mathbf{3 5 0 - 4 0 0}$ & $\mathbf{4 0 0 - 4 5 0}$ & $\mathbf{4 5 0 - 5 0 0}$ & TOTAL & Gas Phase & Liq Phase \\
\hline $\begin{array}{c}\text { Mass } \\
\text { Distribution }\end{array}$ & 30 & 32 & 27 & 10 & 96 & 69 & 31 \\
\hline Sulfur wt\% & 57 & 87 & 95 & 180 & 500 & 68 & 14.8 \\
\hline Paraffins wt\% & 28 & 28 & 30 & 27 & 29 & 28.8 & 28.4 \\
\hline Naphthene wt\% & 31 & 35 & 37 & 39 & 36 & 34 & 38 \\
\hline Aromatics wt\% & 42 & 36 & 34 & 35 & 36 & 36 & 32 \\
\hline
\end{tabular}

\subsection{Kinetics Interpretation}

Previous experimental work done allowed the establishment of the kinetic equations for a simple "lump" of reactions. One species in the model represents one of the four pseudo-component cuts present in the gas and liquid phase. The reactions and the kinetic rate equations considered can be interpreted as shown in Table 6, where two phase model with reactions in gas and liquid phase was used. Flash calculation is incorporated into the model to evaluate the concentration in both phases along the isothermal reactor. Numerical method was used to solve the mass balance along the reactor. The poly-ring aromatics (pe: alkyl-naphthalene) hydrogenation proceeds in series to give a polyringnaphtene-aromatics (pe: alkyl-tetraline) and then poly-rings-naphthenes compounds (ca: alkyldecaline). The poly-rings-naphthenes are hydrogenated in series to open the rings and give paraffins. The complex network of reactions (well described in the literature $[8,9]$ ) need to be solved together with fluid dynamic related parameter (empirical constant $a, b, c)$ using a tricklebed reactor model (7).The ability to convert heavy material into lighter material in the presence of hydrogen is associated with aromatic saturation. This particular catalytic system produced a deep hydrogenation of the aromatics, increasing the naphthenes and paraffin content.

Table6. Reactions and Kinetics Interpretation.

\begin{tabular}{|c|c|c|}
\hline Unit & Reaction & Kinetic \\
\hline HDS & $\begin{array}{c}\text { Aromatics sulfur compound }+H 2 \rightarrow H 2 S+\text { aromatic } \\
\text { compounds }\end{array}$ & $\begin{array}{l}\frac{1}{S f^{0.8}}-\frac{1}{S O^{0.8}} \\
=\left(k_{1} e^{\frac{-18000}{T}}\right) \frac{(P H 2)^{a}\left(\frac{H 2}{H C}\right)^{b}}{(L H S V)^{c}}\end{array}$ \\
\hline MHCK & $\begin{array}{c}\text { Hydrocarbons }+x \mathrm{H} 2 \rightarrow \text { different Hydrocarbons (lighter } \\
\text { products) }\end{array}$ & $\begin{array}{l}\left(\frac{1}{370+f}\right)^{0.5}-\left(\frac{1}{370+o}\right)^{0.5} \\
=\left(k_{2} e^{\frac{-17000}{T}}\right) \frac{(P H 2)^{a}\left(\frac{H 2}{H C}\right)^{b}}{(L H S V)^{c}}\end{array}$ \\
\hline HDAl & $\begin{array}{c}\text { alquil-poly-rings-Aromatics or Alquil-poly-rings } \\
\text { Naphthenes }+\mathrm{H} 2 \rightarrow \text { lighter poly rings Aromatics or } \\
\text { polyrings Naphthenes }\end{array}$ & $\begin{array}{l}\ln \left(1-\frac{\operatorname{Aro}}{\operatorname{Arof}}\right) \\
=\left(k_{3} e^{\frac{-2500}{T}}\right) \frac{(P H 2)^{a}\left(\frac{H 2}{H C}\right)^{b}}{(L H S V)^{c}}\end{array}$ \\
\hline HDA & $\begin{array}{l}\text { Di-rings-aromatics }+3 \mathrm{H} 2 \rightarrow \text { Naph-mono-ring- } \\
\text { Aromatics }+3 \mathrm{H} 2 \rightarrow \text { di-ring Naphthenic compound }\end{array}$ & $\begin{array}{l}\ln \left(1-\frac{A r o}{A r o f}\right) \\
=\frac{\left(k_{3} e^{\frac{-14000}{T}}\right)}{k_{4}+k_{5} e^{\frac{-27000}{T}}} \frac{(P H 2)^{a}\left(\frac{H 2}{H C}\right)^{b}}{(L H S V)^{c}}\end{array}$ \\
\hline HDNp & $\begin{aligned} \text { Di-rings-Naphthenes }+\mathrm{H} 2 & \rightarrow \text { Alkyl-mono - ring } \\
\text { Naphthenes }+\mathrm{H} 2 & \rightarrow \text { Parafins }\end{aligned}$ & $\begin{array}{l}\ln \left(1-\frac{N a f o}{N a f}\right) \\
=\frac{\left(k_{6} e^{\frac{-14000}{T}}\right)}{k_{7}+k_{8} e^{\frac{-27000}{T}}} \frac{(P H 2)^{a}\left(\frac{H 2}{H C}\right)^{b}}{(L H S V)^{c}}\end{array}$ \\
\hline
\end{tabular}


These hydrogenated molecules were cracked by hydrogenolisis to open the rings. The analysis of the type of molecules present in cuts I II III and IV (aromatics parafins and naphthenes) shows that a hydrodealkylation reaction also occurred (see the shift of aromatics toward lower molecular weight in tables 3, 4 and 5. The heavier aromatics in cut III and IV are converted into the lighter aromatics present in cut II first and then in cut I, increasing the aromatics vaporization. The higher the operating pressure, the higher is the poly-aromatics hydrogenation and the naphthenic-paraffinic production (see value of a in table 7). The higher the temperature, the higher is the MHCK and the hydrodealkylation reactions (see activation energies in equations). The HDS reaction was the fastest, followed by aromatics hydrogenation and by MHCK. The polyaromatic hydrogenation occurred quickly for the first ring saturation, but the subsequent hydrogenation rate for the other naphthenic-aromatic molecules was controlled by the thermodynamics hydrogenolisis and hydrodealkylation. The total weight of aromatics slowly decreased when the MHCK increased. Naphthenic ring opening into paraffins is the slowest reaction. The constants of these equations were determined using previous results (3) and confirmed using the experimental data obtained in this work for this feed stocks. To understand the effect of vaporization using the results presented here, the value of the empirical constant $\mathbf{a}, \mathbf{b}$, and $\mathbf{c}$ are presented in Table 7 for 3, 16, and 33\% wt VGO conversion (vaporization 52.5, 60.7 , and $69 \% \mathrm{wt}$ ). They were obtained by integrating the trickle bed (plug flow) reactor model. It can be seen that the coefficient $\mathbf{a}, \mathbf{b}$ and $\mathbf{c}$ need to be adjusted to keep the "same" mathematical expression for the kinetics and reproduce the conversions. The c parameter is reduced when vaporization increases and the value and the trend are similar for the three reactions (HDS HDA and MHCK). This coefficient corrects the residence time $(1 / \mathrm{LHSV})^{\mathrm{c}}$ for the fact that vaporization increases the gas phase flow rate.Figure 3 shows the impact of $\mathbf{b}$ and $\mathbf{c}$ changes on $(\mathrm{PH} 2)^{\mathrm{b}}$ and $(\mathrm{H} 2 / \mathrm{HC})^{\mathrm{c}}$. The first is affecting the hydrogen partial pressure $(\mathrm{PH} 2)^{\mathrm{a}}$. The small change in the a parameter shows in table 6 produces an important reduction in the effective partial pressure (4 to 8\%) for all the reactions (see the columns associated to $\mathrm{PH} 2 \mathrm{a}$ in figure 3- dark gray- and compare the value for HDS, HDA, and MHCK), while the vaporization increases to 15.6 and to $31.4 \%$ by weight respectively.

Table7. Effect of vaporization on $a, b$ and c coefficients.

\begin{tabular}{|c|c|c|c|}
\hline \multicolumn{4}{|c|}{ Vaporization wt\% } \\
\hline & 52.5 & 60.7 & 69.0 \\
\hline \multicolumn{4}{|c|}{ HDS } \\
\hline $\mathrm{a}$ & 0.33 & 0.31 & 0.30 \\
\hline $\mathrm{b}$ & 0.12 & 0.11 & 0.10 \\
\hline $\mathrm{c}$ & 0.82 & 0.76 & 0.70 \\
\hline \multicolumn{4}{|c|}{ HDA } \\
\hline $\mathrm{a}$ & 0.30 & 0.28 & 0.26 \\
\hline $\mathrm{b}$ & 0.14 & 0.14 & 0.13 \\
\hline $\mathrm{c}$ & 0.80 & 0.78 & 0.73 \\
\hline \multicolumn{4}{|c|}{ MHCK } \\
\hline $\mathrm{a}$ & 0.24 & 0.23 & 0.22 \\
\hline $\mathrm{b}$ & 0.10 & 0.09 & 0.07 \\
\hline $\mathrm{c}$ & 0.80 & 0.78 & 0.73 \\
\hline
\end{tabular}

The impact is high for the aromatic hydrogenation and less important for HDS and MHCK. The impact of the $b$ changes is (see light gray columns in figure 3) also the highest for aromatics HDA reaction, where $(\mathrm{H} 2 / \mathrm{HC})^{\mathrm{b}}$ decreases to 8 and to $18 \%$ when vaporization increases to 15.6 and to $31.5 \%$ wt respectively. The impact of the (b) parameter in MHCK and HDS are lower than in HDA. The first parameter $(\mathrm{PH} 2)^{\text {a }}$ changes the "effective" hydrogen partial pressure in the kinetics due to vaporization, and the second $(\mathrm{H} 2 / \mathrm{HC})^{\mathrm{b}}$ impact the "effective" hydrocarbon concentration, reacting in gas and in liquid phase. PROII calculation of hydrogen partial pressure and $\mathrm{H} 2 / \mathrm{HC}$ ratio indicate changes of 5 to $8 \%$ and 1.2 to $3.1 \%$ respectively due to $\mathrm{HC}$ vaporization of 15.6 and $31.5 \%$ by weight. They are relative low modification in comparison to changes predict by kinetics model. For that reason it is suspect that the effect of $a \mathrm{~b}$ and $\mathrm{c}$ parameters might also be associated to fluid dynamic effect (hold up and wetting). The experiment done at high temperature and lower hydrogen partial pressure confirm previous kinetics parameter. 


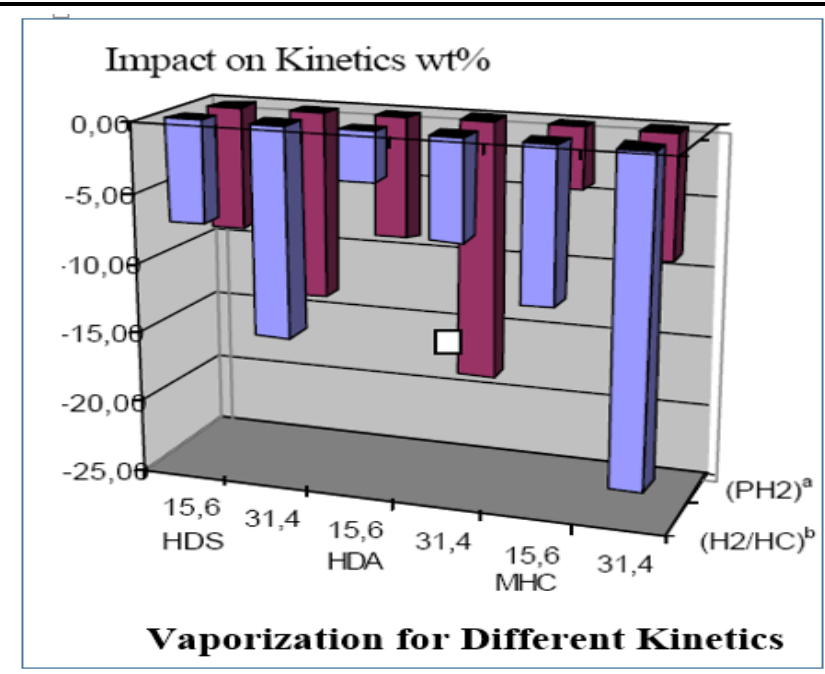

Figure3. Effect of vaporization on kinetics

\subsection{Fluid Dynamics}

The reaction was conducted in a Trickle-Bed mode. Gas and liquid phases flowed through the reactor, contacting the catalyst with different residence time. The real contact time depend on the gas and liquid hold up. A higher vaporization results in higher hydrocarbon concentration in the gas phase, increasing its viscosity, density, and surface tension. In this way the gas and liquid phase properties change as a function of their position in the reactor, since conversion increases through it. The liquid hold up can be calculated using the following equations [satterfierld 10]:

$$
\begin{gathered}
\varepsilon_{l}=\left(\frac{\rho_{l} d p L}{\mu_{l} A}\right)^{0.333}\left(\frac{d p g r l}{\mu_{l}}\right)^{-0.333} \\
\left.\varepsilon_{g}(\text { gas hold up })+\varepsilon_{l} \text { (liquid hold up }\right)=\text { constant }
\end{gathered}
$$

$\rho_{\mathrm{l}}$, and $\mu_{\mathrm{l}}$ are the density and the viscosity of the liquid which depend on temperature (that change from 370 to $420^{\circ} \mathrm{C}$ ), on hydrogenation and slightly on vaporization; dp is the particle diameter and $\Omega$ is the cross sectional area of the reactor. The change calculated in $\varepsilon_{1}$ goes from $19 \%$ to $16 \%$ in the reactor, when the MHCK increases from 3 to $33 \%$ by weight. Gas properties are strongly affect by vaporization (density and viscosity), but the increase in Reynolds and Froude dimensionless numbers (Nre, NFr) in the correlation produce no significant change in gas hold up (eg) that was slightly increased, when vaporization increases from 50 to $78 \%$ along the reactor. That effect is due to the insensitivity of the hold up in this region to gas linear velocity changes. The liquid hold up measured at room temperature and 80 bar of total pressure using hydrogen + propane to represent the gas phase and octane to simulate liquid phase confirm a value of $20 \%$ for it (to be publish later on) and confirm its insensitivity to gas Reynolds number. In addition, the catalysts, wetting by liquid might decreased when the hydrocarbons are converted and transferred from liquid to gas phase along the reactor. The vaporization and chemical reactions produced a small change in liquid properties increasing $\mathrm{HC}$ in gas phase that affect static liquid hold up and internal liquid hold up (mainly by changing inter-phase surface tension). The calculation done according to Charpentier's formula (11) showed a minor (5\%) reduction in static hold up by effect of temperature. The wetting factor is a function of the superficial mass velocity affected by an exponent close to 0.3 according to Mills and Dudokovick [12]. But the lack of experimental value for the properties introduce some error into the calculation in all correlation and the analysis cannot be extended further. Hydrocarbons flowing in gas phase might have different contact if the wetting change. The state of the art reports that upon going into total vaporization, the HDS reaction rate increases. The lumped kinetics model used here considers this reaction take place in gas and liquid phase with the same kinetics. Further improvement could be the use of gas and liquid kinetics as reported by Dassori et al. (13), but seems too difficult to obtain the constant by solving the kinetics, the vaporization and the fluid dynamics simultaneously. The empirical exponent $\mathrm{a}, \mathrm{b}$ and $\mathrm{c}$ used in the kinetics model for the trickle bed reactor to reproduce the experimental results follows the Mears [14] approach to correct LHSV, but using empirical coefficients. They could represent the effect of many complex parameters associated to vaporization, temperature, wetting, residence time, and hydrocarbons reactivity in gas and liquid phase. 


\subsection{Diesel Quality}

The diesel produced by mild hydrocracking reactions contained still a high amount of total aromatics with low cetane number, sulfur and nitrogen (see Table 4 and 5 that shows the quality of the cut C5$350^{\circ} \mathrm{C}$ which is mostly diesel). The unconverted VGO had a slightly lower amount of total aromatics but a higher proportion of naphthenic -aromatics compounds than naphthenic-paraffinics, with respect to the total product $\left(\mathrm{C} 5-500^{\circ} \mathrm{C}\right)$. This study confirmed previous results (7) on the effect of hydrogen partial pressure and $\mathrm{H} 2 / \mathrm{HC}$ ratios on aromatics saturation. It seems that increasing conversion by rising reaction temperature increases vaporization, produce changes in hydrogen partial pressure, $\mathrm{H} 2 / \mathrm{HC}$ ratio and fluid dynamics through the reactor. The increases in conversion by temperature produce an increase in dealkylation of polyaromatics and naphthene-aromatics, and the hydrogenolysis reactions. These are confirmed by the shift of aromatics and naphthenes from heavy (IV) to the light cut (I) and by the increases the C1-C4 produced. Tables 3, 4 and 5 show different aromatics and naphthene distributions in the complete products $(\mathrm{C} 5+)$ for different operating temperature. Figure 4 presents the cetane number of the Diesel obtained form cut I as a function of reaction temperature (Yield on Diesel is also depicted in the figure). Cetane number increases to $42 \%$, when yield in Diesel is $10 \%$ wt $\left(380^{\circ} \mathrm{C}\right)$; then it decreases to $34 \%$ when yield is $27 \%$ wt $\left(420^{\circ} \mathrm{C}\right)$. These results (a maximum in cetane number for $380^{\circ} \mathrm{C}$ ) suggest the possibility of selecting an optimal operating temperature, $\mathrm{H} 2 / \mathrm{HC}$ ratio and space velocity to achieve an optimal compromise in aromatic hydrogenation-mild hydrocracking and hydrodealkylation. The value of the optimal operating temperature can be improved by adding recycling gas compressor capacity (higher $\mathrm{PH} 2$ and $\mathrm{H} 2 / \mathrm{HC}$ ) in existing HDS-MHCK plant; In addition, catalyst life might also be extend (to be proven). The hydrogenation - hydrogenolisis selectivity could be additionally improved by changing the catalytic system.

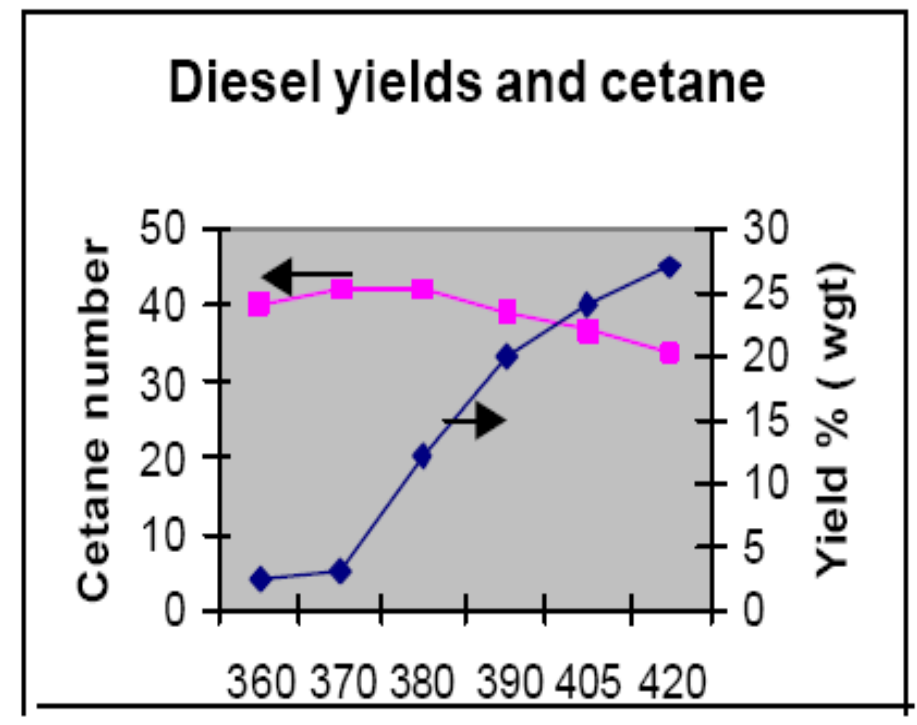

Figure4. Cetane Number as a function of reaction temperature

\section{Conclusions}

The effects of vaporization have been studied using pilot plant data, the analysis of the feed and product obtained in the hot separation system, the simulation of the system with PROII engineering tool, and kinetics modeling the reaction network. It can be concluded that:

- Increasing the operating temperature at constant pressure, at constant space velocity and the $\mathrm{H} 2 / \mathrm{HC}$ in the trickle bed inlet, increase HDS, MHCK, HDA, HDAl, and HDNp reactions. The higher the temperature, the higher the vaporization and the Diesel yield, but the lower the cetane number.

- Vaporization modified the hydrogen partial pressure, the $\mathrm{H} 2 / \mathrm{HC}$ ratio along the reactor, as well as the gas properties of the gas phase. Some fluid dynamics modification in hold up and wetting occurs because hydrocarbons in gas phase change the flow rate and the properties.

- Aromatics, naphthenics and paraffins compound change as a function of MHCK conversion. Poly rings alkyl-aromatics are hydrogenated- and hydrogenolized to polyrings- alkylnaphtenes and then 
to paraffins according with a very well-known path of reaction. In addition, a hydrodealkylation take place and aromatics and naphthenes of lower molecular weight is produced (Diesel cut). That affect the Diesel cetane number that is a function of the amount (and type) of paraffins-naphtenes content. Some aromatics transfer from VGO to Diesel without hydrogenation occurs at high conversion temperature. The selectivity (hydrodealkylation / hydrogenation) may be different in gas phase than in liquid phase.

- Empirical constants $\mathrm{a}, \mathrm{b}$ and $\mathrm{c}$ are included in the kinetics model to take in account the effect of hydrogen partial pressure, hydrogen hydrocarbon ratio and residence time. They need to be modified to take into account vaporization effects in a sever mildhydrocracking operation.

- Gas and liquid phase analytical characterization indicate different concentration of hydrocarbon active species (Aromatics, sulfur, nitrogen) in gas phase than in liquid phase that need to be take in account in the trickle bed model. An additional effort is required to adjust the model using different reactivity in gas and liquid phase.

- PRO II simulation of the vaporization is a little higher than experimental results.

- Diesel quality (cetane number and sulfur) produced in MHCK operation can be optimized adjusting hydrogen partial pressure, $\mathrm{H} 2 / \mathrm{HC}$ ratio, temperature, and type of catalyst.

\section{Nomenclature}

Sf: wt $\%$ of sulfur at the inlet (feed) of the reactor

So: wt $\%$ of sulfur at the outlet of the reactor

\section{$\mathrm{T}$ : Temperature}

$370+\mathrm{f}$ and $370+\mathrm{o}$ are the wt $\%$ of paraffins that distilled over $370^{\circ} \mathrm{C}$

Arf: wt $\%$ of aromatics at the inlet of the reactor

Aro: wt $\%$ of aromatics at the outlet of the reactor

Naff: wt $\%$ of aromatics at the inlet of the reactor

Nafo: wt \% of aromatics at the outlet of the reactor

a: relative effect of vaporization in hydrogen concentration in the gas and liquid phase

b: relative effect of vaporization in $\mathrm{HC}$ concentration in the liquid and gas phase

c: relative effect of vaporization in the residence time in gas and liquid phase

L: liquid volumetric flow rate

$\rho$ : density

$\mu$ : viscosity

\section{REFERENCES}

[1] Prada, R; Galiasso, R; Romero, Y; Reyes, E; and Rodríguez E.; US patent 5558766, Sept.24, 1986.

[2] Galiasso, R.; Di Marco, M and Salazar. A; 13th World Petroleum Congress, proceedings pp. $263,1991$.

[3] Galiasso R, Chisa International Congress, reprint number 123 October 2000.

[4] De Brujin, A.; The 6th. Int. Congress on Catalysis, London, paper B34, 1976.

[5] Joback, K.G. and Reid, RC; Chem Eng Commun, 57, p 233, 1987.

[6] Lee, B.I. and Kesler, M.G.; Aiche J. 21, p 510, 1975.

[7] Galiasso, R.; Rodríguez, E.; Marco, M. and Badra, C.;" Unpublished results (1989).

[8] Yui S M Sanford C A ; ACS Division of Petroleum Chemistry Inc April 1987 p 315-319.

[9] Langlois GE Sullivan R F ; Advan. Chem Sec No 97 1970, p 38-67.

[10] Satterfield, C.N.; Pelosof, A.A. and Shherwood, T.K.; Aiche J.; 15, p226,1969. 
Asem M. AL Jarrah

[11] Charpentier, J.C.; Prost, C. and Le Goff, P.; Chim \& Ind.Genie Chimie, 99, p. 803, 1968.

[12] Mills, P.L.; Dudokovic, M.P.; Aiche. J. 27, p.893,1981.

[13] Dassori, G; Fernández, N.; Arteca, R.; Diaz, A. and Buitrago, S.; Preprint vol 106,p 443, 1997.

[14] Mears, D.E.; Chem. Eng. Sci..; 26, p1361, 1971. 